\title{
Ingestion of n-3 polyunsaturated fatty acids and ovulation in rats
}

\author{
E. P. Trujillo ${ }^{\dagger}$ and K. S. Broughton* \\ Department of Home Economics, College of Agriculture, University of Wyoming, Laramie, \\ WY 82071-3354, USA
}

\begin{abstract}
The effects of different ratios of dietary (n-3):(n-6) polyunsaturated fatty acids on prostaglandin $\mathrm{E}$, prostaglandin $\mathrm{F}_{2 \alpha}$ and ovulation in rats were assessed. Dietary $(\mathrm{n}-3)$ polyunsaturated fatty acids were incorporated, by ovarian phospholipids with ovarian tissue enrichment, with (n-3) polyunsaturated fatty acids enhancing, and (n-6) polyunsaturated fatty acids reducing, the number of ova released in immature rats primed with pregnant mares' serum gonadotrophin and human chorionic gonadotrophin. Incorporation of (n-3) polyunsaturated fatty acids appeared to enhance ovulation by altering total prostaglandin $\mathrm{E}$ production. This effect may be induced by changes in the prostaglandin $\mathrm{E}_{3}: \mathrm{E}_{2}$ ratio and the synthesis of less biologically active prostaglandin $\mathrm{E}_{3}$, or by dilution of the anti-ovulatory properties attributable to prostaglandin $E_{2}$. High incorporation of dietary (n-6) polyunsaturated fatty acids may lead to reduced ovulation through excessive production of prostaglandin $\mathrm{E}_{2}$. Prostaglandin $\mathrm{E}$ or $\mathrm{F}_{2 \alpha}$ and alterations in tissue phospholipid composition inhibited progesterone release, and inhibition was independent of the series of prostaglandin produced. This study provides evidence that dietary lipids affect ovulation in rats with possible implications for reproduction in other vertebrates.
\end{abstract}

\section{Introduction}

The role of prostaglandins (PGs) in ovulation and the effect of pharmacological inhibitors has been investigated (Osman and Dullaart, 1976; Espey, 1983; Satoh et al., 1985; Espey et al., 1986; Brännström et al, 1987; Sogn et al., 1987), but little work has addressed the effect of dietary lipids on PG synthesis in the ovary. The role of dietary (n-3) polyunsaturated fatty acids (PUFAs) and their mode of action in ovulation have not been assessed.

Linoleic acid (18:2n-6), an essential fatty acid found primarily in vegetable oil, is converted to arachidonic acid $(20: 4 n-6)$ by a desaturation and elongation process (Gurr and James, 1975) and is stored in the two position of tissue phospholipids. Upon release by activated phospholipase $A_{2}$ (Cooper and Malik, 1984), arachidonic acid serves as substrate for eicosanoid synthesis via the cyclooxygenase and lipoxygenase pathways (Samuelsson, 1981; Wolfe, 1982; Martin, 1985; Smith, 1992). Eicosapentaenoic acid (20:5n-3), originating primarily from fish and fish oil, reduces the synthesis of eicosanoids through competitive inhibition of the cyclooxygenase, as well as through competition with arachidonic acid for the two position on phospholipids (Wolfe, 1982). A reduction in arachidonic acid metabolites decreases cardiovascular disease in cultures that consume diets that are high in fish (Dyerberg et al., 1978; Hairai et al., 1980). Reductions in arachidonic acid metabolites, induced by the use of pharmacological cyclooxygenase

\footnotetext{
*Correspondence.

†Present address: 7000 College Ave. 185 Bakersfield, CA 93306, USA. Received 4 April 1995.
}

inhibitors such as indomethacin, have been shown to inhibit ovulation (Osman and Dullaart, 1976; Espey, 1983; Satoh et al., 1985; Espey et al., 1986; Brännström et al., 1987; Sogn et al., 1987) through reductions of both $\mathrm{PGF}_{2 u}$ and $\mathrm{PGE}_{2}$.

In a model proposed by Espey (1980), ovulation is characteristic of an inflammatory reaction. This model has been supported by studies before and since its introduction. An ovulatory surge of $\mathrm{LH}$ before ovulation induces a rise in production of cyclic AMP (cAMP), steroidogenesis, and the release of histamine and related compounds that mediate the initial phases of inflammation. During the intermediate stages of ovulation, PGs enhance inflammatory reactions and activate thecal fibroblasts. In the final stages of ovulation, preovulatory follicle-secreted serine proteases activate local collagenases, resulting in a multitude of proteolytic enzymes that degrade follicular connective tissue and thus induce ovulation.

Administration of high concentrations of $\mathrm{PGE}_{2}$ before ovulation in rabbits and hamsters reduces production of ova (Hamada et al., 1977; Martin and Talbot, 1981; Schmidt et al., 1986). Conversely, in isolated rat ovaries, ovulation is inhibited by administering indomethacin resulting in a reduction of $\mathrm{PGE}_{2}$ and $\mathrm{PGF}_{2 u}$ (Sogn et al., 1987) and is restored by the addition of exogenous $\mathrm{PGE}_{2}$. Excess $\mathrm{PGE}_{2}$ is also immunosuppressive (Kinsella et al., 1990), but low concentrations enhance the immune response. Prostaglandins of the 3-series, including $\mathrm{PGE}_{3}$ originating from (n-3) PUFA, are known to be less biologically active (Goodman and Gilman, 1985) than are those of the two-series in endothelial cells (Bordet et al., 1986), platelets (Dyerberg et al., 1978), and the duodenum and ileum (Gurr and James, 1975). 
Diets high in (n-6) PUFA increase the availability of arachidonic acid for eicosanoid synthesis (Kinsella et al., 1990). Because PGs are important mediators of ovulation in rats (Brännström et al., 1987) and humans (Killick and Elstein, 1987), any variable that reduces the availability of arachidonic acid reduces biosynthesis of two-series $P G s$ and thus has the potential to alter ovulation. Ingestion of n-3 PUFA, shown to alter eicosanoid production in other systems by replacing arachidonic acid in tissue phospholipids (Gurr and James, 1975), has the potential to alter ovulation.

This study assessed the effect of various ratios of dietary $(n-3)$ and (n-6) PUFAs on PG synthesis and on ovulation in rats.

\section{Materials and Methods}

\section{Animals}

Sixteen female Sprague-Dawley rats (Charles River Laboratories, Wilmington, MA), at known stages of pregnancy, were individually housed in cages in a room at $25^{\circ} \mathrm{C}$ with controlled humidity on a $12 \mathrm{~h}$ light: $12 \mathrm{~h}$ dark cycle upon arrival. Beginning at day 16 of pregnancy, rats were fed one of three experimental diets or the control diet. At birth, dams remained on their respective diet until the female pups were weaned. Eight days after birth, male pups were killed and equal numbers of females were placed among mothers in the same dietary group. Each experimental group contained 22 female pups. Pups were weaned at day 18 after birth, housed at four pups per cage and maintained on their respective diet. At 25 days of age, pups were given an i.p. injection of 10 iu pregnant mares' serum gonadotrophin (PMSG) (Sigma, St Louis, MO) to stimulate follicular growth, and an i.p. injection of $10 \mathrm{iu}$ hCG (Sigma) $48 \mathrm{~h}$ later. Ovulation occurs $11-13 \mathrm{~h}$ after administration of hCG (Espey et al., 1988). One half of each dietary group was killed by ether inhalation $6 \mathrm{~h}$ after administration of $\mathrm{hCG}$, and concentrations of progesterone and $\mathrm{PG}$ were measured. At $15 \mathrm{~h}$ after hCG, the second half of each dietary group was killed and ova were counted. All studies were approved by the Animal Care and Use Committee at the University of Wyoming.

\section{Diet}

The study lasted for 4 weeks, during which rats were fed one of three experimental diets or the control diet containing $10 \mathrm{~g}$ fat per $100 \mathrm{~g}$. The control diet contained $3.49 \mathrm{~g}(\mathrm{n}-6)$ PUFA per $100 \mathrm{~g}$, while the experimental diets consisted of an (n-6) PUFA diet (N6) with $6.02 \mathrm{~g}(\mathrm{n}-6)$ PUFA per $100 \mathrm{~g}$; a low (n-3) PUFA diet (LN3) with $0.07 \mathrm{~g}(\mathrm{n}-3)$ PUFA and $3.1 \mathrm{~g}(\mathrm{n}-6)$ PUFA per $100 \mathrm{~g}$; and a high (n-3) PUFA diet (HN3) with $2.66 \mathrm{~g}$ (n-3) PUFA and $3.41 \mathrm{~g}$ (n-6) PUFA per $100 \mathrm{~g}$ (Table 1). Sardine oil was the source of (n-3) PUFA in both (n-3) PUFAcontaining diets. Olive oil served as the filler oil in all diets.

\section{Analysis of prostaglandin and progesterone}

At $6 \mathrm{~h}$ after $\mathrm{hCG}$ administration, ovarian concentrations of $\mathrm{PGF}_{2 u^{\prime}}$ PGE and progesterone were determined by enzymelinked immunoassay (Cayman Chemical Company, Ann Arbor,
Table 1. Fatty acid composition of experimental diets $\left(\mathrm{g} \mathrm{kg}^{-1}\right)$ consumed by rats

\begin{tabular}{lcccc}
\hline & \multicolumn{4}{c}{ Dietary groups ${ }^{\ddagger}$} \\
\cline { 2 - 5 } Fatty acid & N6 & Control & HN3 & LN3 \\
\hline n-6 & & & & \\
n-3 & 60.22 & 34.92 & 34.11 & 31.05 \\
Total PUFA & 00.00 & 00.00 & 26.55 & 06.83 \\
& 60.22 & 34.92 & 50.67 & 37.88 \\
\hline
\end{tabular}

${ }^{\ddagger}$ Control diet: (n-6) PUFA set at the lowest concentration in all diets (the same concentration as that found in LN3 and HN3 diets); N6 diet: approximately double the (n-6) PUFA content of the control diet; LN3 diet: (n-6):(n-3) PUFA at approximate 1:0.2 ratio; HN3 diet: (n-6):(n-3) PUFA at approximate 1:1 ratio. PUFA: polyunsaturated fatty acids.

MI). Ovaries from individual animals were homogenized, with a single pass of a dounce homogenizer, in $2 \mathrm{ml}$ cold Dulbecco's PBS solution (Dulbecco and Vogt, 1954) combined with $5 \mathrm{ml}$ petroleum ether and $6 \mathrm{ml}$ acetone. After pelleting the tissue by centrifugation $(500 \mathrm{~g}, 4 \mathrm{~min})$, the petroleum ether phase was removed for $\mathrm{PG}$ analysis, while the acetone phase was used for progesterone analysis. After validation of enzyme-linked immunoassay kits through serial dilutions and best fit to a standard curve, standard volumes of homogenate extractions were used for PG and progesterone analysis.

\section{Number of ova}

Fifteen hours after hCG administration, half of each dietary group were killed; the oviducts were removed and placed between dissecting microscope slides and ova were counted (Espey et al., 1988; Daud et al., 1990).

\section{Fatty acid separation and analysis}

After centrifugation and isolation of the ovarian homogenate pellet, phospholipid fatty acids from the ovarian pellet and perfused livers were extracted by a modification of the method of Bligh and Dyer (1959). Briefly, livers were perfused with a saline, EDTA buffer $(0.9 \%(\mathrm{w} / \mathrm{v}) \mathrm{NaCl}, 5 \mathrm{mmol}$ EDTA $\left.\mathrm{I}^{-1}\right)$ and a portion was homogenized at $100 \mathrm{mg}$ saline $\mathrm{ml}^{-1}$. Both ovarian and liver lipids were extracted from the homogenate with chloroform:methanol $(1: 2, \mathrm{v}: \mathrm{v})$, and then by chloroform:saline $(1: 1, v: v)$, and then twice by chloroform (Lokesh et al., 1988). Chloroform extracts were isolated, evaporated to dryness under nitrogen and the residual lipids were redissolved in chloroform. Phospholipids were separated by thin layer chromatography (TLC) using a chloroform:methanol $(8: 1, v: v)$ solvent system and visualized with $0.01 \%(\mathrm{w} / \mathrm{v})$ 8-hydroxy-1,3,6-pyrene-trisulfonic acid trisodium salt in methanol (Goswami et al., 1981). Phospholipids were recovered from the TLC plate by scraping and were saponified in toluene and $0.5 \mathrm{~mol} \mathrm{KOH} \mathrm{^{-1 }}$ in methanol for $8 \mathrm{~min}$ at $86^{\circ} \mathrm{C}$ before acidification with $0.7 \mathrm{~mol} \mathrm{HCl} \mathrm{l}^{-1}$ in methanol. Fatty acids were extracted with hexane and methylated with ethereal diazomethane (Swanson et al., 1987). Methyl esters were redissolved in hexane and analysed by gas chromatography, using a $0.25 \mathrm{~mm} \times 30 \mathrm{~m}$ capillary column (J \& W 
Table 2. Fatty acid composition (mol per $100 \mathrm{~mol}$ ) of phospholipids extracted from rat liver tissue ${ }^{1}$

\begin{tabular}{|c|c|c|c|c|}
\hline \multirow[b]{2}{*}{ Fatty acid } & \multicolumn{4}{|c|}{ Dietary groups } \\
\hline & N6 & Control & $\mathrm{HN} 3$ & LN3 \\
\hline $14: 0$ & $0.12 \pm 0.0$ & $0.12 \pm 0.0$ & $0.14 \pm 0.0$ & $0.9 \pm 0.0$ \\
\hline $16: 0$ & $26.7 \pm 0.0$ & $28.8 \pm 0.4$ & $31.5 \pm 0.9$ & $28.4 \pm 0.5$ \\
\hline $16: 1$ & $0.55 \pm 0.1$ & $2.06 \pm 0.4$ & $1.86 \pm 0.4$ & $1.99 \pm 0.3$ \\
\hline $18: 0$ & $27.6 \pm 0.7$ & $23.3 \pm 0.3$ & $28.2 \pm 1.2$ & $24.1 \pm 0.7$ \\
\hline $18: 1$ & $9.6 \pm 0.3^{\mathrm{a}}$ & $13.3 \pm 0.4^{\mathrm{ab}}$ & $9.65 \pm 0.5^{a}$ & $13.2 \pm 1.2^{b}$ \\
\hline $18: 2 n-6$ & $10.4 \pm 0.3^{b}$ & $8.06 \pm 0.2^{a}$ & $10.8 \pm 0.3^{b}$ & $10.5 \pm 0.2^{\mathrm{b}}$ \\
\hline $20: 3 n-6$ & $0.36 \pm 0.1^{\mathrm{a}}$ & $0.29 \pm 0.0^{\mathrm{a}}$ & $0.74 \pm 0.1^{b}$ & $0.59 \pm 0.0^{b}$ \\
\hline $20: 4 n-6$ & $17.6 \pm 0.4^{\mathrm{c}}$ & $18.2 \pm 0.9^{c}$ & $5.58 \pm 0.2^{\mathrm{a}}$ & $10.4 \pm 0.4^{\mathrm{b}}$ \\
\hline $20: 5 n-3$ & $0.01 \pm 0.0^{\mathrm{a}}$ & $0.01 \pm 0.0^{\mathrm{a}}$ & $3.92 \pm 0.2^{c}$ & $2.29 \pm 0.1^{b}$ \\
\hline $22: 4 n-6$ & $0.87 \pm 0.1^{\mathrm{c}}$ & $0.48 \pm 0.0^{b}$ & $0.01 \pm 0.0^{a}$ & $0.01 \pm 0.0^{2}$ \\
\hline $22: 5 n-6$ & $5.04 \pm 0.3^{b}$ & $4.12 \pm 0.1^{\mathrm{b}}$ & $0.10 \pm 0.0^{a}$ & $0.05 \pm 0.0^{\mathrm{a}}$ \\
\hline $22: 5 n-3$ & $0.14 \pm 0.0^{\mathrm{a}}$ & $0.10 \pm 0.0^{a}$ & $0.89 \pm 0.0^{\mathrm{b}}$ & $0.84 \pm 0.0^{b}$ \\
\hline $22: 6 n-3$ & $1.11 \pm 0.1^{\mathrm{a}}$ & $1.22 \pm 0.0^{\mathrm{a}}$ & $6.80 \pm 0.4^{\mathrm{b}}$ & $7.56 \pm 0.3^{b}$ \\
\hline $\mathrm{n} 6 / \mathrm{n} 3$ & $22.3 \pm 1.6^{\mathrm{d}}$ & $18.0 \pm 0.7^{b}$ & $0.58 \pm 0.0^{\mathrm{a}}$ & $1.05 \pm 0.0^{\mathrm{b}}$ \\
\hline EPA $/ A A$ & $0.00 \pm 0.0^{\mathrm{a}}$ & $0.00 \pm 0.0^{\mathrm{a}}$ & $0.70 \pm 0.0^{c}$ & $0.22 \pm 0.0^{\mathrm{b}}$ \\
\hline n6 & $23.8 \pm 0.6^{c}$ & $23.0 \pm 0.2^{\mathrm{c}}$ & $6.44 \pm 0.2^{a}$ & $11.0 \pm 0.4^{b}$ \\
\hline $\mathrm{n} 3$ & $1.26 \pm 0.1^{a}$ & $1.33 \pm 0.1^{\mathrm{a}}$ & $11.6 \pm 0.7^{b}$ & $10.7 \pm 0.5^{b}$ \\
\hline Total PUFA & $35.5 \pm 0.6^{c}$ & $32.4 \pm 0.2^{b c}$ & $28.9 \pm 0.9^{a}$ & $32.2 \pm 0.9^{\mathrm{ab}}$ \\
\hline $\mathrm{UI}^{2}$ & $138.52 \pm 1.7^{b c}$ & $135.54 \pm 0.9^{\mathrm{b}}$ & $123.04 \pm 0.6^{a}$ & $140.86 \pm 0.4^{c}$ \\
\hline
\end{tabular}

${ }^{1}$ Values are means \pm SEM of 22 experimental values. Means with the same superscript within the same row are not significantly different $(P>0.05)$, Duncan's protected least significant difference test.

${ }^{2}$ Unsaturation Index $=$ UI. [ $\Sigma$ (number of double bonds in each fatty acid) $\times(\mathrm{mol}$ per $100 \mathrm{~mol}$ of each fatty acid)] (Goodwin, 1985).

PUFA: polyunsaturated fatty acids; EPA: eicosapentaenoic acid; AA: arachidonic acid.

Chromatography, Folsom, CA) on a Hewlett-Packard 5890 gas chromatograph, with hydrogen as the carrier gas.

\section{Statistical analyses}

The number of replicates for each assay was determined by statistical analyses of the power to detect a physiologically significant difference between treatments. On the basis of previous experiments, for a $95 \%$ confidence of detecting a $15 \%$ change in PG concentration, the number of replicates required is 11. Experimental groups were analysed by a randomized complete block design to control for possible diurnal variations in the parameters examined. Differences between means for all data were assessed by ANOVA using MSUSTAT (Montana State University). When there were overall differences, specific differences were assessed using Duncan's protected least significant differences test at $P<0.05$. Pearson correlation coefficients were computed between egg production and ovarian $(n-6)$ and (n-3) PUFA status and specific lipids. Values are expressed as means $\pm \operatorname{SEM}(n=11)$.

\section{Results}

\section{Body mass}

At 28 days of age, animals from the control group, with an average mass of $57.5 \pm 0.94 \mathrm{~g}$, had significantly higher average body masses than did animals on the experimental diets, $51.1 \pm 1.45,54.7 \pm 1.09$, and $55.3 \pm 0.87 \mathrm{~g}$ for $\mathrm{HN} 3, \mathrm{~N} 6$, and LN3 animals, respectively.

\section{Phospholipid fatty acids}

Hepatic linoleic acid concentrations were significantly higher in animals consuming the experimental diets $(P<0.05)$ when compared with animals ingesting the control diet (Table 2). Hepatic arachidonic acid was significantly lower $(P<0.05)$ in the HN3 and LN3 groups when compared with the control and N6 groups, with arachidonic acid in animals from the HN3 group lower than those in the LN3 group $(P<0.05)$. With increasing (n-3) PUFA intake, hepatic eicosapentaenoic acid, docosapentaenoic acid (22:5n-3), and docosahexaenoic acid (22:6n-3) concentrations were significantly increased $(P<0.05)$ in comparison with animals consuming the high (n-6) PUFA and control diets. Tissue (n-6) PUFA concentrations in the N6 and control groups were significantly higher than those found in the two (n-3) PUFA-consuming groups. Total PUFA content remained fairly stable across all groups, with lower PUFA concentrations in the two fish oil groups compared with the No dietary group. The overall reduction in total PUFA in the (n-3) PUFA-consuming groups resulted in a reduction of the hepatic unsaturation index (UI). The HN3 group displayed a lower UI than did all other dietary groups $(P<0.05)$, while the LN3 group had a UI significantly higher than that of animals consuming the control diet $(P<0.05)$.

Ovarian phospholipid saturated fatty acids, i.e. myristate (14:0), palmitate (16:0), and stearate (18:0) and the monounsaturated fat, oleic acid (18:1) differed little between dietary groups (Table 3). Concentrations of linoleic acid in the ovaries did not vary between animals consuming the experimental diets but, as with hepatic tissue, they were significantly 
Table 3. Fatty acid composition ( $\mathrm{mmol}$ per $100 \mathrm{mmol}$ ) of phospholipids extracted from rat ovarian tissue ${ }^{1}$

\begin{tabular}{|c|c|c|c|c|}
\hline \multirow[b]{2}{*}{ Fatty acid } & \multicolumn{4}{|c|}{ Dietary groups } \\
\hline & N6 & Control & $\mathrm{HN} 3$ & LN3 \\
\hline $14: 0$ & $0.34 \pm 0.1$ & $0.54 \pm 0.2$ & $0.38 \pm 0.1$ & $0.34 \pm 0.0$ \\
\hline $16: 0$ & $21.2 \pm 0.9$ & $18.6 \pm 0.7$ & $20.1 \pm 0.9$ & $21.3 \pm 0.8$ \\
\hline 16:1 & $1.96 \pm 0.3$ & $1.07 \pm 0.2$ & $1.95 \pm 0.4$ & $1.64 \pm 0.2$ \\
\hline $18: 0$ & $24.0 \pm 1.1$ & $25.4 \pm 1.4$ & $25.6 \pm 1.3$ & $26.1 \pm 0.8$ \\
\hline $18: 1$ & $19.8 \pm 2.2$ & $21.6 \pm 1.5$ & $20.6 \pm 1.0$ & $20.1 \pm 0.6$ \\
\hline $18: 2 n-6$ & $8.67 \pm 0.5^{\mathrm{b}}$ & $7.53 \pm 0.5^{\mathrm{a}}$ & $9.46 \pm 0.4^{b}$ & $8.57 \pm 0.2^{b}$ \\
\hline $20: 3 n-6$ & $0.59 \pm 0.1^{\mathrm{a}}$ & $0.90 \pm 0.1^{\mathrm{ab}}$ & $1.07 \pm 0.2^{\mathrm{ab}}$ & $0.82 \pm 0.1^{b}$ \\
\hline $20: 4 n-6$ & $13.0 \pm 0.7^{\mathrm{b}}$ & $12.2 \pm 0.9^{\mathrm{b}}$ & $9.77 \pm 0.5^{\mathrm{a}}$ & $11.4 \pm 0.7^{\mathrm{ab}}$ \\
\hline $20: 5 n-3$ & $1.15 \pm 0.2^{\mathrm{a}}$ & $1.65 \pm 0.3^{\mathrm{ab}}$ & $2.69 \pm 0.3^{b}$ & $2.24 \pm 0.5^{\mathrm{ab}}$ \\
\hline $22: 4 n-6$ & $4.32 \pm 0.2^{c}$ & $3.15 \pm 0.4^{\mathrm{b}}$ & $0.83 \pm 0.3^{\mathrm{a}}$ & $1.06 \pm 0.2^{\mathrm{a}}$ \\
\hline $22: 5 n-6$ & $2.93 \pm 0.2^{b}$ & $3.37 \pm 0.3^{b}$ & $1.74 \pm 0.3^{a}$ & $1.52 \pm 0.2^{\mathrm{a}}$ \\
\hline $22: 5 n-3$ & $0.68 \pm 0.1^{\mathrm{a}}$ & $1.57 \pm 0.3^{\mathrm{b}}$ & $2.61 \pm 0.2^{c}$ & $2.03 \pm 0.1^{\mathrm{cb}}$ \\
\hline $22: 6 n-3$ & $1.37 \pm 0.2^{\mathrm{a}}$ & $2.43 \pm 0.3^{b}$ & $3.21 \pm 0.2^{\mathrm{b}}$ & $2.88 \pm 0.2^{\mathrm{b}}$ \\
\hline $\mathrm{n} 6 / \mathrm{n} 3$ & $13.4 \pm 2.9^{c}$ & $5.14 \pm 0.8^{b}$ & $2.30 \pm 0.5^{\mathrm{a}}$ & $2.28 \pm 0.2^{\mathrm{a}}$ \\
\hline $\mathrm{EPA} / \mathrm{AA}$ & $0.09 \pm 0.0^{\mathrm{a}}$ & $0.14 \pm 0.0^{b}$ & $0.29 \pm 0.0^{\mathrm{d}}$ & $0.19 \pm 0.1^{c}$ \\
\hline n6 & $20.8 \pm 0.9^{\mathrm{b}}$ & $19.6 \pm 1.4^{\mathrm{b}}$ & $13.4 \pm 0.8^{\mathrm{a}}$ & $14.8 \pm 0.7^{\mathrm{a}}$ \\
\hline $\mathrm{n} 3$ & $3.20 \pm 0.5^{\mathrm{a}}$ & $5.65 \pm 0.8^{\mathrm{b}}$ & $8.51 \pm 0.7^{c}$ & $7.15 \pm 0.5^{\mathrm{cb}}$ \\
\hline Total PUFA & $32.7 \pm 1.0$ & $32.8 \pm 1.1$ & $31.4 \pm 0.6$ & $30.5 \pm 0.8$ \\
\hline $\mathrm{UI}^{2}$ & $142.17 \pm 3.3^{\mathrm{ab}}$ & $149.36 \pm 2.4^{b}$ & $141.54 \pm 2.8^{\mathrm{ab}}$ & $137.41 \pm 2.3^{\mathrm{a}}$ \\
\hline
\end{tabular}

${ }^{1}$ Values are means \pm SEM of 22 experimental values. Means with the same superscript within the same row are not significantly different $(P>0.05)$, Duncan's protected least significant difference test.

${ }^{2}$ Unsaturation Index $=$ UI. $[\Sigma$ (number of double bonds in each fatty acid) $\times(\mathrm{mol}$ per $100 \mathrm{~mol}$ of each fatty acid)] (Goodwin, 1985).

EPA: eicosapentaenoic acid; AA: arachidonic acid; PUFA: polyunsaturated fatty acids.

higher than in animals consuming the control diet. Phospholipid arachidonic acid concentrations were significantly lower in HN3 animals in relation to N6 and control animals. Animals consuming the (n-6) PUFA-enriched diet had ovarian (n-6):(n-3) ratios five times higher than that found in animals consuming the (n-3) diet. This effect was attributable to a combination of increased $(n-6)$ PUFA concentration in the ovaries of animals consuming the N6 diet, and increased (n-3) PUFA concentrations in the tissues of animals ingesting the (n-3) PUFA diets. While total ovarian PUFA concentrations remained stable across all diets $(P<0.05)$, the UI was significantly lower in the ovaries of animals on the LN3 dietary regimen when compared with that of the control animals. However, the UI did not differ between animals consuming the three experimental diets.

\section{Egg release}

Egg release was significantly lower in N6 animals $(P<0.05)$ when compared with that of HN3 animals (Fig. 1), but neither differed from the LN3 or control animals. Egg production displayed a strong inverse correlation with content of arachidonic acid in the ovaries $(r=-0.82, P<0.04\}$.

\section{Prostaglandin production}

At $6 \mathrm{~h}$ after $\mathrm{hCG}$ administration, $\mathrm{PGF}_{2 \alpha}$ concentrations in the LN3 and N6 groups were significantly higher $(P<0.05)$ than in animals on the control diet (Table 4), while those in the HN3 animals were not different from any of the other three dietary

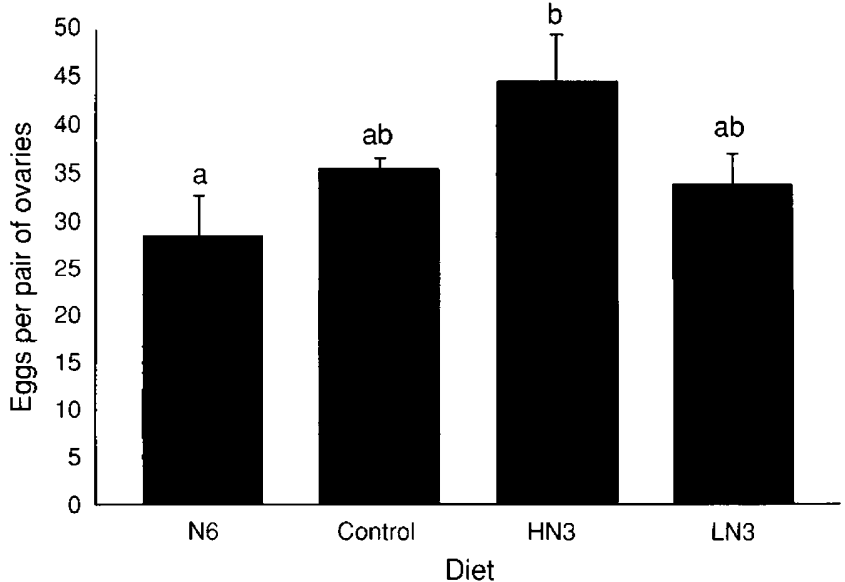

Fig. 1. Egg production $15 \mathrm{~h}$ after hCG administration. Values are means \pm SEM of 11 experimental values. Dietary groups with the same letters above the columns are not significantly different $(P>0.05)$, Duncan's protected least significant difference test. Rats were fed the control (3.49 g (n-6) PUFA per $100 \mathrm{~g})$, N6 (6.02 g (n-6) PUFA per $100 \mathrm{~g}), \mathrm{LN} 3(0.07 \mathrm{~g}(\mathrm{n}-3)$ and $3.1 \mathrm{~g}(\mathrm{n}-6)$ PUFA per $100 \mathrm{~g})$, and HN3 $(2.66 \mathrm{~g}(\mathrm{n}-3)$ and $3.41 \mathrm{~g}(\mathrm{n}-6)$ PUFA per $100 \mathrm{~g}$ ) diets for 4 weeks, and were stimulated with 10 iu PMSG and $48 \mathrm{~h}$ later, with $10 \mathrm{iu}$ hCG. PUFA: polyunsaturated fatty acids; PMSG: pregnant mares' serum gonadotrophin.

groups. Prostaglandin E production at $6 \mathrm{~h}$ after hCG administration was nine times higher than $\mathrm{PGF}_{2 u}$ concentrations at the same time point. Prostaglandin E concentrations were significantly higher in the experimental groups when compared with 
Table 4. Prostaglandin and progesterone biosynthesis in rats (ng per pair of ovaries $6 \mathrm{~h}$ after administration of $\mathrm{hCG})^{\mathrm{T}}$

\begin{tabular}{|c|c|c|c|c|}
\hline & \multicolumn{4}{|c|}{ Dietary groups } \\
\hline & No & Control & $\mathrm{HN} 3$ & LN3 \\
\hline $\mathrm{PGF}_{2 u}$ & $31.63 \pm 2.71^{b}$ & $19.29 \pm$ & $22.88 \pm \quad 3.44^{\mathrm{ab}}$ & $24.89 \pm 2.61^{b}$ \\
\hline PGE & $231.51 \pm 13.75^{b}$ & $174.65 \pm 18.49^{\mathrm{a}}$ & $236.86 \pm 17.83^{b}$ & $227.57 \pm 14.45^{\mathrm{b}}$ \\
\hline Progesterone & $1863.40 \pm 421.72^{\mathrm{ab}}$ & $2397.51 \pm 355.72^{b}$ & $1390.07 \pm 152.17^{\mathrm{a}}$ & $2176.73 \pm 280.32^{\mathrm{ab}}$ \\
\hline
\end{tabular}

${ }^{\mathrm{I}}$ Values are means \pm SEM of 11 experimental values. Dietary groups with the same superscript are not significantly different $(P>0.05)$, Duncan's protected least significant difference test. Rats were fed the control, N6 $(6.02 \mathrm{~g}(\mathrm{n}-6)$ PUFA per $100 \mathrm{~g})$, LN3 (0.07 g (n-3) and $3.1 \mathrm{~g}(\mathrm{n}-6)$ PUFA per $100 \mathrm{~g})$, and HN3 $(2.66 \mathrm{~g}(\mathrm{n}-3)$ and $3.41 \mathrm{~g}(\mathrm{n}-6)$ PUFA per $100 \mathrm{~g})$ for 4 weeks, and were stimulated with 10 iu PMSG and, 48 h later, with 10 iu hCG.

the control group. While the HN3 group had the highest PGE concentrations, they did not differ from the N6 or LN3 groups. The dietary group with lowest $\mathrm{PGF}_{2 u}$ and PGE concentrations was the control group.

\section{Progesterone production}

At $6 \mathrm{~h}$ after hCG administration, the HN3 group had significantly lower progesterone concentrations than did the control group $(P<0.05$; Table 4). The N6 and LN3 groups did not differ from the control or HN3 groups.

\section{Discussion}

The mean mass of rats consuming the control diet was significantly higher than that of animals on the experimental diets, but body mass did not influence ovulation, as the number of eggs produced in the control animals did not differ from that of experimental animals. While the average lowest body mass was found in animals consuming the high (n-3) PUFA diet, this group produced the greatest number of eggs, indicating that low weight is not a confounding factor for ovulation.

At similar intakes of total dietary PUFA, the fatty acid compositions of phospholipids of both liver and ovarian tissue were markedly altered by dietary substitution of $(n-3)$ for $(n-6)$ PUFA. While there was a modest decrease in total hepatic PUFA in the high and low (n-3) PUFA-consuming groups, total PUFA remained relatively stable in hepatic tissue for all dietary groups. A significant reduction in (n-6) PUFA was evident in (n-3) PUFA-consuming groups in both tissues examined. As dietary (n-3) PUFA concentrations were increased, arachidonic acid $(20: 4 n-6)$ and its elongation products, that is, $22: 4 n-6$ and 22:5n-6, were replaced by (n-3) PUFA in liver and ovarian tissue, as has been observed in liver (Hwang et al., 1988; Lokesh et al., 1988). The low (n-3) PUFA group incorporated nearly as much total (n-3) PUFA in hepatic and ovarian tissue phospholipids as did the high (n-3) group, even though there was approximately $25 \%$ as much (n-3) PUFA in its diet. These results indicate that, once a threshold of (n-3) PUFA intake is attained, no further increase in tissue (n-3) PUFA incorporation in ovarian or hepatic tissue is possible without significant increases in (n-3) PUFA intake.
The number of eggs released $15 \mathrm{~h}$ after administration of hCG was similar to the number found in other studies conducted in rats (Espey et al., 1988; Daud et al., 1990; Wilken et al., 1990), while other investigators have reported only half the number (Mori et al., 1977, 1980; Kohda et al., 1983). Egg production was inversely related to ovarian phospholipid arachidonic acid incorporation, with the high (n-3) PUFAconsuming group having the highest egg production and the lowest arachidonic acid concentrations in ovarian phospholipids. Conversely, the (n-6) PUFA-consuming group had the lowest egg production and the highest ovarian incorporation of arachidonic acid. While egg release had a strong inverse correlation with incorporation of arachidonic acid into ovarian phospholipid, progesterone production did not correlate with the number of eggs produced, and no pattern could be identified that related the two parameters. These findings indicate that the number of ova may display a stronger relationship with arachidonic acid concentrations in ovarian tissue than with progesterone involved in ovulation.

The enzyme-linked immunoassay performed to determine $\mathrm{PGE}_{2}$ and $\mathrm{PGF}_{2 a}$ concentrations lacks the antibody specificity to differentiate between the 2- and 3-series PGs. It is possible that (n-3) PUFA consumption resulted in increased production of 3-series PGs. Because PGs of the 3-series are less biologically active (Gurr and James, 1975; Dyerberg et al., 1978; Goodman and Gilman, 1985; Bordet et al., 1986) than those of the 2-series, 3-series PG production could have the potential to affect ovulation differentially, depending on the relative effect and biopotency of $\mathrm{PGE}_{2}$ versus $\mathrm{PGF}_{2 u^{\prime}}$ as well as the potential amount of $\mathrm{PGE}_{3}$ and $\mathrm{PGF}_{3 \alpha}$ produced. Because $\mathrm{PGE}_{2}$ administration before ovulation reduces ova production in rabbits and hamsters (Hamada et al., 1977; Martin and Talbot, 1981; Schmidt et al, 1986), it would appear that $\mathrm{PGE}_{2}$ exerts a powerful influence in ovulation, as would appear to have been demonstrated in the present study. The diet causing the lowest ovulatory rate was the (n-6) PUFA-enriched diet, an effect that may have been induced through overwhelming production of $\mathrm{PGE}_{2}$ and suppression of ovulation in the same manner that high $\mathrm{PGE}_{2}$ concentrations suppress the immune response (Kinsella et al., 1990). Consumption of the high (n-3) PUFA diet resulted in greater ova release, possibly reflecting increases in the production of a potentially less biologically potent $\mathrm{PGE}_{3}$ or a decrease in $\mathrm{PGE}_{2}$ biosynthesis, resulting in an enhancement of 
ovulation, induced through alleviation of the suppressive effect of $\mathrm{PGE}_{2}$. Ova release in response to consumption of the control diet was not statistically lower than that seen in animals consuming the high (n-3) PUFA-enriched diet and resulted in higher ova release when compared with animals consuming the high ( $n-6)$ PUFA diet. The effect in the control animals could have differed from animals consuming the (n-6) PUFA-enriched diet through lower incorporation of arachidonic acid into ovarian tissue and hence lower concentrations of $\mathrm{PGE}_{2}$ production, as evidenced by the experimental data. These results, high PGE production in the high (n-3) PUFA animals and high ova release coupled with the control results indicate that significant amounts of the less biopotent $\mathrm{PGE}_{3}$ may have been produced. This increase in $\mathrm{PGE}_{3}$ production by the high (n-3) PUFA-consuming animals potentially blocks or negates $\mathrm{PGE}_{2}$ production, thus enhancing egg release by directly affecting the ovaries.

Kato (1982) observed that progesterone production is reduced when PGs are administered to LH-primed rats. It was hypothesized that progesterone production was reduced through inhibition by PG of enzymes involved in progesterone synthesis. In the present study, the group with the lowest total PG production, i.e., the control group, had the highest progesterone production, whereas animals consuming the (n-6) and (n-3) PUFA-enriched diets displayed the highest PG concentrations with lower progesterone production. It would appear that inhibition of progesterone synthesis by PGs is confirmed by the present study. Furthermore, it would appear that inhibition of progesterone production may not be PG series-dependent, unlike ova release, hence the lowest progesterone production was evident in the high (n-3) group, the group with the highest total PG production. However, the absolute effect of total PG, PG class, and PG series on progesterone production and release still needs to be ascertained.

The results reported here show that dietary (n-3) PUFA can be incorporated into ovarian phospholipids and that dietary manipulation of ovarian phospholipids can affect the number of ova released in rats primed with PMSG and hCG. Incorporation of (n-3) PUFA into ovarian tissues results in enhanced ovulation, possibly through reduced $\mathrm{PGE}_{2}$, and any potential antiovulatory properties associated therewith, and the possible production of a less biologically active $\mathrm{PGE}_{3}$. High incorporation of (n-6) PUFA into the ovaries reduces ovulation through overproduction of $\mathrm{PGE}_{2}$. Finally, although (n-3) PUFA ingestion enhances ovulation, potentially through changes in the ratio of 2:3-series PGs, progesterone production appeared to be inhibited by PGs, an effect that was independent of the series of PG produced. This study provides evidence that dietary lipids affect ovulation in rats, with possible implications in reproduction of other mammals. Questions arise regarding optimal (n-6) and $(n-3)$ PUFA intake and the potential deleterious affect of excessive (n-6) PUFA intake on the ovulatory process in humans. Furthermore, if (n-3) and (n-6) PUFA consumption exerts an effect, would consumption of fish be beneficial in women with ovulatory difficulty?

This work was supported by the University of Wyoming Agriculture Experiment Station.

\section{References}

Bligh EG and Dyer WJ (1959) A rapid method of total extraction and purification Canadian Journal of Biochemistry and Phsyiology $37911-917$

Bordet JC, Guichardant M and Lagard M (1986) Arachidonic acid strongly stimulates prostaglandin $\mathrm{I}_{3}\left(\mathrm{PGI}_{3}\right)$ production from eicosapentaenoic acid in human endothelial cells Biochemical and Biophysical Research Communications $135403-410$

Brännström M, Koos RD, LeMaire WJ and Janson PO (1987) Cyclic adenosine $3^{\prime}, 5^{\prime}$-monophosphate-induced ovulation in the perfused rat ovary and its mediation by prostaglandins Biology of Reproduction 37 1047-1053

Cooper CL and Malik KU (1984) Effect of glucocorticoids on vascular reactivity to vasoactive hormones in rat isolated kidney-lack of a relationship to prostaglandins British Journal of Pharmacology 82 679-688

Daud AI, Bumpus FM and Husain A (1990) Characterization of angiotensin I-converting enzyme $(A C E)$-containing follicles in the rat ovary during the estrus cycle and effects of ACE inhibitor on ovulation Endocrinology 126 $2927-2935$

Dulbecco R and Vogt M (1954) Plaque formation and isolation of pure lines with poliomyelitis viruses Journal of Experimental Medicine 99 167-182

Dyerberg J, Bang HO, Stoffersen E, Moncada S and Vane JR (1978) Eicosapentaenoic acid and prevention of thrombosis and atherosclerosis? Lancet $\mathbf{1 5}$ $117-119$

Espey LL (1980) Ovulation as an inflammatory reaction-A hypothesis Biology of Reproduction 22 73-106

Espey LL (1983) Comparison of the effect of nonsteroidal and steroidal anti-inflammatory agents on prostaglandin production during ovulation in the rabbit Prostaglandins 26 71-77

Espey LL, Norris C and Saphire D (1986) Effect of time and dose of indomethacin on follicular prostaglandins and ovulation in the rabbit Endocrinology $119746-752$

Espey LL, Kohda H, Mori T and Okamura $\mathrm{H}$ (1988) Rat ovarian prostaglandin levels and ovulation as indicators of the strength of non-steroidal antiinflammatory drugs Prostaglandins 36 875-879

Goodman LS and Gilman AG (1985) The Pharmacological Basis of Therapeutics $\mathrm{p}$ 661. Macmillan Publishing Company, New York

Goodwin IS (1985) Prostaglandins and Immunity. Martinus Nijhoff, Boston

Goswami S, Mai J, Bruckner G and Kinsell JE (1981) Extraction and purification of prostaglandins and thromboxane from biological samples for gas chromatographic analysis Prostaglandins 225 693-702

Gurr MI and James AT (1975) Lipid Biochemistry: An Introduction pp 39-60. Halsted Press, New York

Hamada Y, Bronson RA, Wright KH and Wallach EE (1977) Ovulation in the perfused rabbit ovary: the influence of prostaglandins and prostaglandin inhibitors Biology of Reproduction 17 58-63

Hirai A, Hamazaki T, Terano T, Nishikawa T, Tamura $Y$ and Kumagai A (1980) Eicosapentaenoic acid and platelet function in Japanese Lancet 22 1132-1133

Hwang DH, Boudreau M and Chanmugam P (1988) Dietary linolenic acid and longer-chain ( $\mathrm{n}-3)$ fatty acids: comparison on arachidonic acid metabolism in rats Journal of Nutrition 118 427-437

Kato K (1982) Effect of prostaglandins and human chorionic gonadotropin on steroidogenesis by proestrus rat ovary in vitro Prostaglandins Leukotrienes and Medicine 8 579-592

Killick S and Elstein M (1987) Pharmacologic production of luteinized unruptured follicles by prostaglandin synthetase inhibitors Fertility and Sterility 47 773-777

Kinsella JE, Lokesh B, Broughton KS and Whelan J (1990) Dietary polyunsaturated fatty acids and eicosanoids: potential effects on the modulation of inflammatory and immune cells: an overview Nutrition 5 24-44

Kohda H, Mori T, Nishimura T and Kambegawa A (1983) Co-operation of progesterone and prostaglandins in ovulation induced by human chorionic gonadotropin in immature rats primed with pregnant mare serum gonadotropin Joural of Endocrinology 96 387-393

Lokesh BR, Black JM, German JB and Kinsella JE (1988) Docosahexaenoic acid and other dietary polyunsaturated fatty acids suppress leukotriene synthesis by mouse peritoneal macrophages Lipids 23 968-972

Martin CR (1985) Textbook of Endocrine Physiology (2nd Edni pp 631-632. Oxford University Press, New York

Martin GG and Talbot P (1981) Drugs that block smooth muscle contraction inhibit in vivo ovulation in hamsters Journal of Experimental Zoology 216 483-491 
Mori T, Suzuki A, Nishimura T and Kambegawa A (1977) Inhibition of ovulation in immature rats by anti-progesterone antiserum Journal of Endocrinology 73 185-186

Mori T, Kohda M, Kinoshita Y, Morimoto N and Nishimura T (1980) Inhibition by indomethacin of ovulation induced by human chorionic gonadotrophins in immature rats primed with pregnant mare serum gonadotrophin Journal of Endocrinology $84333-334$

Osman P and Dullaart J (1976) Intraovarian release of eggs in the rat after indomethacin treatment at pro-estrus Journal of Reproduction and Ferfility $\mathbf{4 7}$ 101-103

Samuelsson B (1981) Prostaglandins, thromboxanes, and leukotrienes: formation and biological roles Harvey Lectures 75 1-40

Satoh K, Kinoshita K and Tsutsumi $O$ (1985) Prostaglandins and ovulation Advances in Prostaglandins, Thromboxanes, and Leukotriene Research 15 593-595

Schmidt G, Holmes PV, Owman CH, Sjoberg NO and Walles B (1986) The influence of prostaglandin $\mathrm{E}_{2}$ and indomethacin on progesterone production and ovulation in the rabbit ovary perfused in vitro Biology of Reproduction 35 $815-821$

Smith WL (1992) Prostanoid biosynthesis and mechanisms of action: editorial review American Physical Society News F181-F191

Sogn JH, Curry TE, Brannstrom M, LeMaire WJ, Koos RD, Papkoff $\mathbf{H}$ and Janson PO (1987) Inhibition of follicle-stimulating hormone-induced ovulation by indomethacin in the perfused rat ovary Biology of Reproduction 36 536-542

Swanson JE, Black JM and Kinsella JE (1987) Dietary (n-3) polyunsaturated fatty acids: rate and extent of modification of fatty acyl composition of lipid classes of mouse lung and kidney Journal of Nutrition 177 824-832

Wilken C, Van Kirk EA, Slaughter RG, Ji T and Murdoch WJ (1990) Increased production of ovarian thromboxane in gonadotropin-treated immature rats: relationship to the ovulatory process Prostaglandins 40 637-646

Wolfe LS (1982) Eicosanoids: prostaglandins, thromboxanes, leukotrienes, and other derivatives of carbon-20 unsaturated fatty acids Journal of Neurochemistry 38 1-14 